\title{
Multiple effects of $\beta$-amyloid on single excitatory synaptic connections in the PFC
}

\author{
Yun Wang ${ }^{1,2 *}$, Thomas H. Zhou ${ }^{2}$, Zhina Zhi ${ }^{1}$, Amey Barakat ${ }^{2}$, Lynn Hlatky and Henry Querfurth ${ }^{3}$ \\ 1 School of Ophthalmology and Optometry and Eye Hospital, Wenzhou Medical University, Wenzhou, Zhejiang, China \\ 2 Steward St. Elizabeth's Medical Center, Tufts Medical School, Tufts University, Boston, MA, USA \\ ${ }^{3}$ Department of Neurology, Rhode Island Hospital, Brown University, Providence, RI, USA
}

Edited by:

Ludovic Martin, Université de

Nantes, France

Reviewed by:

Patrick Dutar, INSERM, France

Filippo Tempia, University of Turin, Italy

Fernando Peña, UNAM, Mexico

\section{*Correspondence:}

Yun Wang, School of Ophthalmology

and Optometry and Eye Hospital,

Wenzhou Medical University, 270

Xueyuan Road, Wenzhou, 325003,

Zhejiang, China

e-mail: yun.wang@mail.eye.ac.cn;

wangy62@gmail.com
Prefrontal cortex (PFC) is recognized as an AD-vulnerable region responsible for defects in cognitive functioning. Pyramidal cell (PC) connections are typically facilitating (F) or depressing (D) in PFC. Excitatory post-synaptic potentials (EPSPs) were recorded using patch-clamp from single connections in PFC slices of rats and ferrets in the presence of $\beta$-amyloid $(A \beta)$. Synaptic transmission was significantly enhanced or reduced depending on their intrinsic type (facilitating or depressing), $A \beta$ species (A $\beta 40$ or $A \beta 42)$ and concentration (1-200 nM vs. 0.3-1 $\mu \mathrm{M})$. Nanomolar $A \beta 40$ and $A \beta 42$ had opposite effects on F-connections, resulting in fewer or increased EPSP failure rates, strengthening or weakening EPSPs and enhancing or inhibiting short-term potentiation [STP: synaptic augmentation (SA) and post-tetanic potentiation (PTP)], respectively. High A 40 concentrations induced inhibition regardless of synaptic type. D-connections were inhibited regardless of $A \beta$ species or concentration. The inhibition induced with bath application was hard to recover by washout, but a complete recovery was obtained with brief local application and prompt washout. Our data suggests that $A \beta 40$ acts on the prefrontal neuronal network by modulating facilitating and depressing synapses. At higher levels, both $A \beta 40$ and $A \beta 42$ inhibit synaptic activity and cause irreversible toxicity once diffusely accumulated in the synaptic environment.

Keywords: $\beta$-amyloid $(A \beta)$, synaptic connection, synaptic dynamics, excitatory post-synaptic potential (EPSP), short term potentiation (STP), synaptic augmentation (SA), post-tetanic potentiation (PTP)

\section{INTRODUCTION}

In patients and animal models of the early stages of Alzheimer's Disease $(\mathrm{AD})$, declines in episodic or spatial memory and cognition are correlated with an increase in brain levels of soluble $\beta$-amyloid (A $\beta$ ) (Lue et al., 1999; Walsh et al., 2002; Rowan et al., 2003). A causal link between the accumulation of $A \beta$ in a soluble, toxic state and impairment of neuronal mechanisms that support memory was demonstrated in a mature $\beta A P P$ transgenic mouse model wherein a single systemic injection of an antibody to $A \beta$ eliminated the memory deficit (Dodart et al., 2002). There is a major focus on the synapse as the initial site of damage in AD (Selkoe, 2002; Nimmrich and Ebert, 2009). Synaptic dysfunction as a consequence of diffusible $A \beta$ is also inferred from studies showing reduced basal transmission and altered plasticity (Klyubin et al., 2005; Shankar et al., 2008; Minano-Molina et al., 2011). In anatomic terms, synapse numbers are reduced early in some AD brain regions (Davies et al., 1987), especially in the prefrontal cortex (PFC) and medial temporal lobe (Morris and Baddeley, 1988). Meanwhile, additional studies in the recent decade indicate that low levels of $A \beta$ peptides could be essential for the modulation of synaptic plasticity (Parihar and Brewer, 2010).

In $\mathrm{AD}$, limbic and association cortices are selectively involved while primary cortical areas remain relatively preserved. These regions of neuronal vulnerability in fact correspond to the degree to which neuronal plasticity can be demonstrated in them
(Arendt, 2001). The PFC is a critical association region associated with executive type cognitive function. PFC also orchestrates a unique form of short-term memory termed "working memory." Working memory is a limited capacity system that supports nonroutine types of daily activity. It is a temporary storage system for maintaining and rapidly manipulating information, and is closely connected with attention, strategic information flow and action (Goldman-Rakic, 1996). Experimentally, prefrontal cortical neurons are found to remain persistently active during the delay between sensory cue and an executed response task. The ongoing activity, an electrical correlate of working memory, is stable to the interference from distractors (Goldman-Rakic, 1995). Further, fMRI studies confirm the role of PFC in strategic encoding and goal directed control over the retrieval process in episodic type memory processes (Simons and Spiers, 2003). Less appreciated than episodic memory, working memory is also impaired in the early stages of $\mathrm{AD}$, according to clinical and in vivo studies (Morris and Baddeley, 1988). Impairment of PFC function may precede the pathological changes of $\mathrm{AD}$ in other cortical association areas (Reid et al., 1996). Correspondingly, soluble $\mathrm{A} \beta$ accumulates in the PFC to one of the highest and earliest levels across several cortical regions in the pre-tangle stages of $\mathrm{AD}$ (Gouras et al., 2000) and in transgenic mice (Zhuo et al., 2008). Tangle formation in the PFC is also highly correlated with the transition to clearly recognizable dementia (Wang and $\mathrm{Al}$, 2001). 
In the PFC network, excitatory synaptic connections in layer $\mathrm{V}$ show both facilitated (F-connection) and depressed (D-connection) excitatory post-synaptic potentials (EPSPs) in response to short train stimuli (Wang et al., 2006). F-connections are formed predominantly by complex-type pyramidal cells (PCs) which feature dual apical dendrites, a high degree of interconnectivity and of reciprocity in chemical synaptic connections. In contrast, D-connections are typically formed by simple PCs that are common to primary cortices. A computer simulation study revealed that these facilitating synapses play a crucial role in the formation of persistent neuronal activity, consistent with the properties of working memory (Mongillo et al., 2008). The critical role of the PFC in working memory and early involvement in $\mathrm{AD}$ make it a suitable region to examine the electrophysiologic effects of $A \beta$.

Numerous studies of $\mathrm{AD}$-promoting factors (e.g., $\mathrm{A} \beta$ ) have examined their effects on field electrophysiological characteristics in the hippocampus and cortex. Because of competing synaptic inputs and influences from other local networks, the use of field recordings may account for seemingly contradictory early reports, where $A \beta$ either increased excitability through membrane depolarization and enhancing long term potentiation (LTP) or depressed both synaptic transmission and LTP induction (Wu et al., 1995; Selkoe, 2002; Walsh et al., 2002; Esteban, 2004; Puzzo et al., 2008; Li et al., 2011). Up until now, a study focused on activity-dependent plasticity specific to the association cortex has not been reported. It is therefore timely to carry out an investigation of an in situ neural network, especially at the resolution of individual synaptic connections, within an association cortical area such as the PFC.

In this study, using multi-neuron patch clamp recording from PFC slices, we found that synaptic responses of single excitatory synaptic connections were significantly enhanced or reduced depending on their intrinsic type (facilitating or depressing), the tested $A \beta$ species (40 or 42 amino acids) and concentration (low dose 1-200 nM vs. high dose 0.3-1 $\mu \mathrm{M}$ ). Low-doses of $\mathrm{A} \beta 40$ enhanced F-connections and inhibited D-connections in the PFC. In contrast, high-doses of A $\beta 40$ and low-doses of $A \beta 42$ inhibited all types of excitatory synaptic connections. Further, the inhibition induced with bath application was commonly difficult to recover or even became worse by washout. However, direct local and brief application of the peptides by pipette at comparable concentrations produced similar inhibitions with a rapid and complete recovery upon washout. Based on the principles of synaptic dynamics that have been well-studied in our previous computer simulation of synaptic responses of single synaptic connections, the effects of $\mathrm{A} \beta$ were considered to be produced via both pre- and post-synaptic mechanisms.

\section{MATERIALS AND METHODS ELECTROPHYSIOLOGICAL RECORDINGS}

Prefrontal cortical slices were prepared using a published protocol (Wang et al., 2006). Briefly, brain was dissected from normal adolescent Wistar rats (day 25-35) or young adult ferrets (7-9 weeks old). PFC slices $(300 \mu \mathrm{M})$ were sectioned using a vibratome (DTK 1000 Zero 1 Microslicer) and then incubated in artificial cerebrospinal fluid (ACSF) before transfer to a recording chamber (at $34^{\circ} \mathrm{C}$ ). Neurons in layer $\mathrm{V}$ of the medial PFC were visually identified using infrared differential contrast videomicroscopy (BX50WI, Olympus). An advanced technique consisting of quadruple patch clamp recording was used to record from candidate cell bodies (somata), and single synaptic connections formed between neuron pairs were determined electrophysiologically according to standard characteristics of chemical synaptic transmission (Wang et al., 2006). Somatic whole-cell signals (6-12 $\mathrm{m} \Omega$ pipette resistance) were amplified using Axoclamp200B amplifiers (Axon Instruments, USA). Recordings were sampled over real time and filtered using the program Igor (Igor Wavemetrics, Lake Oswego, OR, USA), digitized by an ITC18 interface (Instrutech, Great Neck, NY, USA) and stored on hard drive (Macintosh G5 computer) for off-line analysis (Igor). Stimulating and voltage recording glass micropipettes were filled with $(\mathrm{mM})$ : 100 potassium gluconate, $20 \mathrm{KCl}, 4$ ATP-Mg, 10 phosphocreatine, $0.3 \mathrm{GTP}, 10$ Hepes ( $\mathrm{pH} 7.3$ ) and $0.4 \%$ biocytin (Sigma). Presynaptic action potentials (AP) were elicited using short (3 ms), suprathreshold, intracellular depolarizing current pulses. The extracellular recording solution consisted of ACSF, containing (mM): $125 \mathrm{NaCl}, 2.5 \mathrm{KCl}, 25$ glucose, $25 \mathrm{NaHCO}_{3}$, $1.25 \mathrm{NaH}_{2} \mathrm{PO}_{4}, 2 \mathrm{CaCl}_{2}$, and $1 \mathrm{MgCl}_{2}$. Only neurons with stable access resistance were included in the statistical analyses. Membrane potentials were routinely voltage-clamped at $-70 \pm$ $2 \mathrm{mV}$ to maintain $\mathrm{Vm}$ against drift by using small current injections. Neurons were filled with $0.4 \%$ biocytin (Sigma) by diffusion at the end of the recordings for later identification of neuronal types.

Once synaptic connections were obtained, the EPSP failure rate, certain dynamic features of EPSPs and short term potentiation components including synaptic augmentation (SA) and post-tetanic potentiation (PTP), were recorded (Wang et al., 2006). For the EPSP failure rate, single APs were repeatedly evoked $(0.5 \mathrm{~Hz}, 15-30$ times $)$ in a presynaptic cell and the number of corresponding EPSP failures in a postsynaptic cell were counted. For the synaptic dynamic features, an EPSP train was evoked by $6-8$ presynaptic APs at $10-20 \mathrm{~Hz}$ followed by a recovery test response (RTR) after a $500 \mathrm{~ms}$ delay. SA and PTP were induced by giving a 15 pulse (tetanus) stimulus at $50 \mathrm{~Hz}$. Single test responses $(0.5 \mathrm{~Hz})$ were recorded for $20 \mathrm{~s}$ before and up to $100 \mathrm{~s}$ after the train. This procedure was repeated four times, each preceded by a 2 min interval.

\section{HISTOLOGICAL PROCEDURES AND 3D COMPUTER RECONSTRUCTION}

After recording, the slices bearing biocytin-injected neurons were fixed for at least $24 \mathrm{~h}$ in cold $0.1 \mathrm{M}$ phosphate buffer saline (PBS, pH 7.4) containing 2\% paraformaldehyde, $1 \%$ glutaraldehyde, and $0.3 \%$ saturated picric acid. Thereafter, the slices were rinsed several times (10 min each) in PBS. To block endogenous peroxidases, slices were transferred into phosphate-buffered $3 \%$ $\mathrm{H}_{2} \mathrm{O}_{2}$ for 10-30 min. After five to six rinses in PBS (10 min each), slices were incubated overnight at $4^{\circ} \mathrm{C}$ in avidin-biotinylated horseradish peroxidase according to the manufacturer's protocol (ABC-Elite, Vector Labs, Petersborough, UK) (2\% A, 2\% $\mathrm{B}$, and $1 \%$ Triton-100). Following incubation and additional rinses, the reaction was developed with diaminobenzidine (DAB) under visual control using a bright-field microscope (Zeiss, NY, 
USA) until all cell processes appeared clearly visible (usually after 2-4 $\mathrm{min}$ ). The reaction was stopped upon transferring the sections into PBS. Slices were mounted in aqueous mounting medium.

3D neuron models were reconstructed from stained cells using the Neurolucida system (MicroBrightField Inc., USA) and a bright-field light microscope (Olympus, BX51, Japan). Reconstructed neurons subsequently underwent quantitative analysis using the NeuroExplorer (MicroBrightField Inc., USA; $\times 60$ magnification, numerical aperture $=0.9 ; \mathrm{Z}$-axis resolution $=0.37 \mu \mathrm{m})$. Putative synapses were identified according to the criteria as published (Wang et al., 2002).

\section{PREPARATION AND TREATMENT OF SOLUBLE SYNTHETIC A $\beta$}

Soluble synthetic $A \beta$ peptides $(A \beta 40, A \beta 25-35$, and $A \beta 42)$ were purchased from Biosource (Camarillo, CA) or the Harvard Protein Core laboratory and prepared as $0.1 \mathrm{mM}$ stock following published methods and stocked at $-80^{\circ} \mathrm{C}$ (Stine et al., 2003). The quality of monomer stock solutions were examined periodically using western blots [NuPAGE Novex 4-12\% Bis-Tris gels (Invitrogen)] (Figure A1). Mouse monoclonal anti-human amyloid beta protein antibody (6E10, purchased from Signet) was used at a 1000X dilution. Horse anti-mouse IgG HRP-linked antibody (Cell Signaling Technology, 2000X dilution) was used as secondary antibody and the development with Chemiluminol that followed was captured on hyperfilm (Amersham Biosciences). Different concentrations of $A \beta$ were freshly prepared before use by defrosting and diluting the stock solution with ACSF. Only monomer predominant stock solution was used in the current study. Soluble A $\beta$ was bath-applied either at low dosage (1$200 \mathrm{nM})$ or at high dosage $(300 \mathrm{nM}-1 \mu \mathrm{M}$ ) (see Chen et al., 2000). During recording, brain slices were continuously perfused with oxygenated ACSF at a flow rate of $0.75-1.0 \mathrm{ml} / \mathrm{min}$. The ACSF volume in the tube leading to and including the recording chamber was $1.5-2.0 \mathrm{ml}$. This enabled quick replacement of the recording solutions $(\leq 3 \mathrm{~min}$.) when switching between experimental procedures. Each recording procedure was repeated under three conditions: (1) pre-application, (2) application, and (3) washout of $A \beta$. The $A \beta$ application recordings typically lasted for $30 \mathrm{~min}$. whereas washout recordings lasted for 10-30 $\mathrm{min}$.

\section{MODELING ANALYSIS OF SYNAPTIC RESPONSES}

The quantitative analysis of basal synaptic dynamic properties of excitatory connections has been carried out using a wellknown computer model of a combination of EPSP train and a RTR evoked with a $500 \mathrm{~ms}$ delay (Markram et al., 1998; Tsodyks et al., 2000; Wang et al., 2006). The RTR is used to test the recovery of synaptic facilitation or depression, which characterizes the synapse type. The model extracts four key parameters of the connection: DFUA ( $D$, the time constant of recovery from depression (ms); $F$, the time constant of recovery from facilitation (ms); $U$, utilization of synaptic resources, analogous to the neurotransmitter release probability $(p) ; A$, the absolute strength of a synaptic connection ( $\mathrm{nA}$ ), defined as its maximum response when $p=1$ ). This modeling approach is based on fitting the mean output behavior of synaptic connections and therefore requires inputting only averaged responses (i.e., average EPSP traces). Generally speaking, reductions in A correspond to the situation when the amplitudes of all EPSPs in the train and RTR become smaller, keeping an unchanging EPSP pattern. In the case of reductions in $U$, the amplitude of the 1st EPSP is reduced whereas subsequent EPSPs are facilitated. When normalized to the first EPSP in such recordings, the subsequent EPSP amplitudes, but not the RTR, are magnified. In the case of a larger $D$ value, both EPSPs (subsequent to the 1st) and the RTR show reductions. Oppositely, a high value for the parameter $F$ correlates to the situation in which both EPSPs (subsequent to the 1st) and the RTR are increased.

\section{STATISTICAL ANALYSIS}

Paired student $t$-test was used to compare EPSP responses between different conditions: [(1) pre-application, (2) application, and (3) washout of $A \beta$.]. Unpaired student $t$-test was used for the comparison of EPSP responses between different treatments of A $\beta$. The statistical analyses of EPSP train, SA and PTP were all based on an intrinsic comparison of individual single synaptic connections between the $A \beta$ application or washout condition with the pre-application condition. In order to lessen the influence from the variance of synaptic strength between individual connections, the statistical comparisons were made using normalized values. In the analysis of EPSP train, all EPSP values of a connection were normalized to the mean of EPSPs recorded under the pre-application condition. In the analysis of SA and PTP, all EPSP values of a connection were normalized to the mean of pre-tetanus EPSPs obtained in the pre-A $\beta$ application condition. Furthermore, an EPSP pattern defined by a certain "8-EPSP train + RTR" configuration for each type of synapse, allowed each EPSP value to be treated as an independent outcome value in the statistical comparison. Multiple outcome values per connection were therefore used in the EPSP train analysis. The same principle was also applied to the analyses of SA and PTP.

\section{RESULTS}

Quadruple patch clamp recording was performed to record synaptically coupled pairs $(n=100)$ in layer V of the PFC of rats $(n=92$, age P25-P35) and ferrets $(n=8$, age $7-9$ weeks old). Since synaptic dynamics (i.e., depressing and facilitating types) of synapses are consistent across species (Wang et al., 2006), the data of the two species were pooled together in order to maximally utilize the obtained data. The studied connections comprise synapses formed between PCs (PC-PC, $n=86$ pairs) and those formed by a $\mathrm{PC}$ onto an interneuron (PCIN, $n=14$ pairs) (Figure 1). The neuronal type was identified according to the morphology (PCs and interneurons-mainly basket cells and Marttinoti cells) combined with the firing pattern of APs evoked by depolarizing current steps injected into neuronal somata (Wang et al., 2002, 2006). EPSP responses of a postsynaptic cell were induced by APs evoked by brief depolarizing current injections delivered into the presynaptic neuronal soma. We previously characterized the excitatory neuronal network in layer V of the PFC (Wang et al., 2006). Facilitationdominant synapses (F-connections) are abundant in the PFC while depression-dominant synapses (D-connections), typically common in primary cortical areas, form a minor population in 


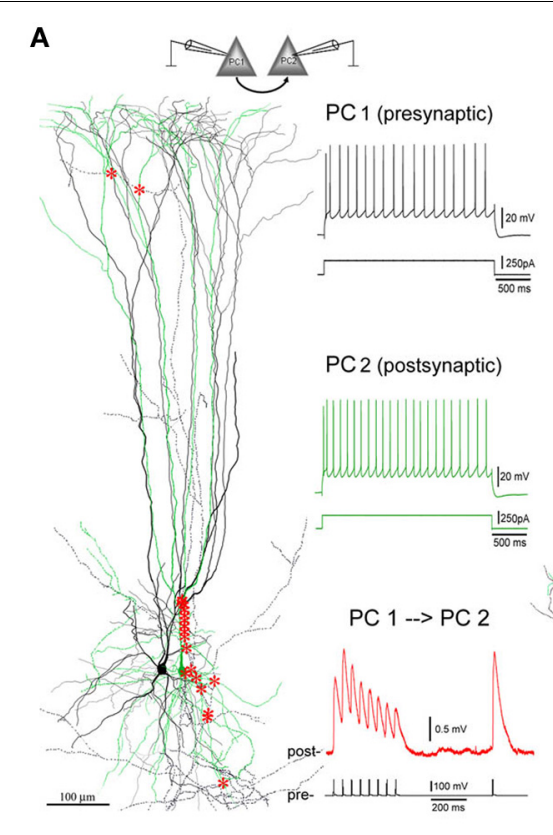

FIGURE 1 | Excitatory synaptic connections in layer V of PFC. (A) A facilitating (F-type) PC-PC connection in layer V of the PFC of an 8-weeks old ferret. Left panel: 3D computer reconstruction of the connection: Both pre(PC1 in black) and post-synaptic (PC2 in green) cells are complex PCs featured by an apical dendrite with multiple early-bifurcated major branches. A total of 20 putative synapses are marked with red stars onto the basal, apical, oblique and tuft dendrites of PC2. Right panel: Physiological responses of pre- (upper, in black) and post-synaptic (middle, in green) cells were induced by injections of depolarization currents into their somata. Excitatory postsynaptic potentials (EPSPs, down, in red) were recorded from PC2 by giving brief current injections

\section{B}

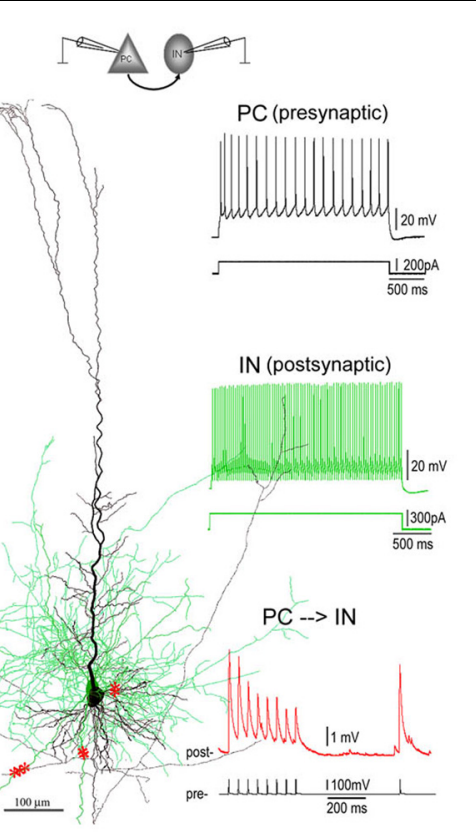

to induced action potentials (APs, bottom, in black) in PC1. The postsynaptic response train is composed of 8 EPSPs at a $20 \mathrm{~Hz}$ frequency followed by a recover test response (RTR) with 500 ms delay. (B) A depressing (D-type) PC-IN connection in layer $\mathrm{V}$ of the PFC of a P30 rat. The color coding for the reconstructed pre- and post-synaptic cells and their physiological and synaptic responses are the same as the PC-PC connection in (A). A total of 7 putative synapses are marked with red stars onto basal dendrites of the postsynaptic interneuron. Note: The postsynaptic interneuron appears to be a fast-spiking basket cell according to its axonal and dendritic morphologies and fast AP firing induced by depolarization current injection to its soma. the PFC. In order to examine effects of beta-amyloid peptides $(\mathrm{A} \beta 40, \mathrm{~A} \beta 25-35, \mathrm{~A} \beta 42)$ on single $\mathrm{F}-$ and D-connections, low(1-200 $\mathrm{nM})$ and high-dosages $(0.3-1 \mu \mathrm{M})$ of $\mathrm{A} \beta$ were continuously bath-applied while recording of EPSPs. The failure rate, synaptic dynamics and STP were investigated. The experimental procedure of applying $\mathrm{A} \beta$ was successfully performed in $48 \%$ of recorded connections (48 out of 100 pairs: rats, PC-PC, $n=$ 35 pairs and PC-IN, $n=7$ pairs; ferrets, PC-PC, $n=6$ pairs). Unfortunately, synaptic responses of the other 52 connections became unstable or even disappeared in the middle of $A \beta$ application. These unstable connections were excluded from the data analysis.

\section{INFLUENCES OF A $\beta$ ON FAILURE RATES OF F- AND D-CONNECTIONS}

Presynaptic APs can fail to induce the release of neurotransmitter resulting in failures of evoked EPSPs. F-connections generally display higher failure rates than do D-type connections because the initial release probability of F-connections is usually lower. Single APs in presynaptic cells were generated at $0.5 \mathrm{~Hz}$ and EPSP failure rates of $\mathrm{F}$ - and D-connections were observed, respectively, under conditions of pre-application (in ACSF only), A $\beta$ application and washout. An example of widening transmission failure in an F-type synapse exposed to $1 \mu \mathrm{M} \mathrm{A} \beta 40$ and moderate recovery upon washout is given in Figure 2A. Surprisingly, we found that lower doses of $A \beta 40$ tended to reduce the synaptic failure rate in
F-connections. In contrast, the transmission failure rate became increased under all other studied conditions, including low-dose $\mathrm{A} \beta 40$-bathed D-connections, high-dose $\mathrm{A} \beta 40$ or low-dose $\mathrm{A} \beta 42$ applied to F- or D-connections (Figure 2B). The increase in failure rate was statistically significant for the cases of low and high doses of $\mathrm{A} \beta 40$ to $\mathrm{D}$-connections $(P=0.01$ and $P=0.024$, respectively). A trend toward higher failure rate, although not statistically significant, was clearly visible in the cases of high-dose $\mathrm{A} \beta 40$ to F-connection $(n=3)$ and low-dose $\mathrm{A} \beta 42$ to F- $(n=3)$ and $\mathrm{D}$ - $(n=4)$ connections. The opposing directions in failure of synaptic responses was present in Figure 2C, wherein, the net failure reduction in the case of low-dose $\mathrm{A} \beta 40$ to F-connections was opposite in direction to the net failure increase in all other cases. After washout for 10-30 min, these contrasting net changes in failure rates virtually remained (Figure 2D). Note the failure rate was further increased in the case of low-dose $\mathrm{A} \beta 42$ to F- and D-connections following washout (Figure 2B, far right set: compared with pre-application, $P=0.04$; compared with $\mathrm{A} \beta$ application, $P=0.05$ ). This phenomenon indicates that $\mathrm{A} \beta 42$ is selectively more toxic to synaptic connections in the PFC.

\section{DIFFERENTIAL EFFECTS OF A $\beta$ ON SYNAPTIC DYNAMICS OF F- AND D-CONNECTIONS}

EPSP trains generated by 5-8 APs and RTR $500 \mathrm{~ms}$ later were used in a phenomenological modeling strategy to estimate dynamic 
A

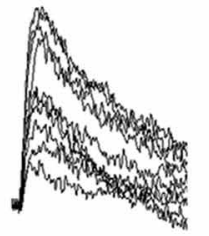

control

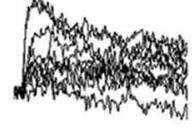

$1 \mu \mathrm{M} \mathrm{A} \beta$

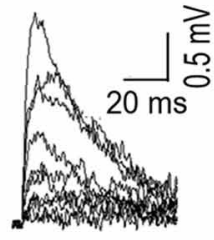

washout

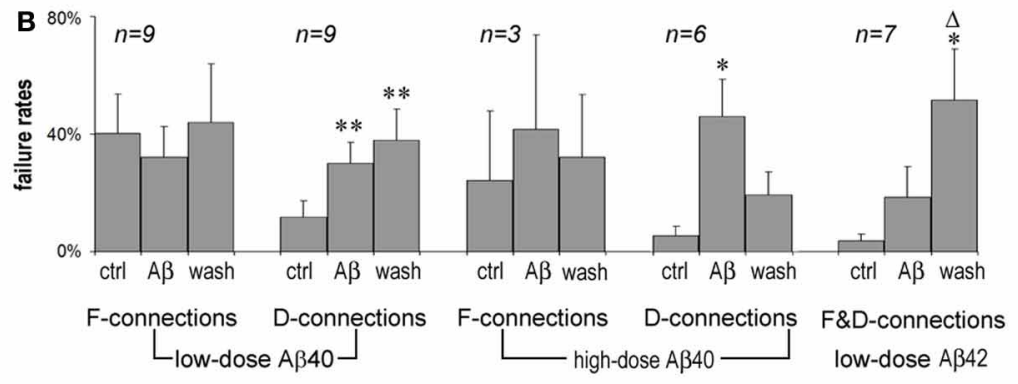

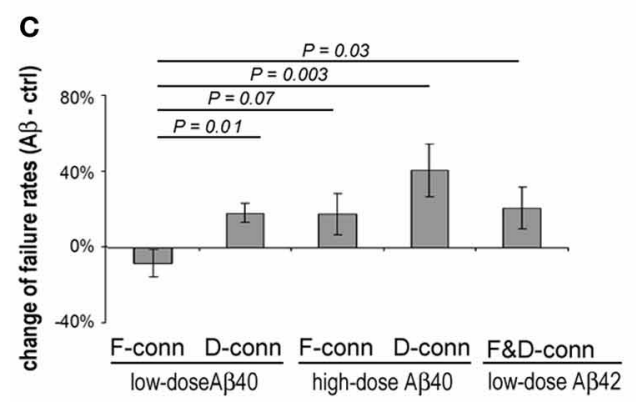

FIGURE 2 | Synaptic failure rates vary according to synaptic type and upon $\mathbf{A} \boldsymbol{\beta}$ species and concentration. (A) Superimposed 15 single EPSP traces recorded at $0.5 \mathrm{~Hz}$ from an F-type connection in pre-application, application and washout phases of $1 \mu \mathrm{M}$ A $A 40$. EPSPs were generally reduced and the number of failures increased during application of $A \beta$ for $20 \mathrm{~min}$, which tended to recover on washout for $10 \mathrm{~min}$. (B) Average failure rates of $\mathrm{F}$ - and $\mathrm{D}$-connections in pre-application, application and washout phases in the presence of $A \beta$ were charted according to $A \beta$ species and concentration, and connection type. The synaptic failure rate tended to decrease in F-connections after low-dose A 40 applied. In contrast, the failure rates appear to increase in all other cases. Low and high doses of A $\beta 40$ applied to $D$-connections reached significance $(P=0.01$ and $P=0.024$, respectively). A trend to enhance failure rates is shown in the case of high-dose $A \beta 40$ to F-connection $(n=4)$ and low-dose A $\beta 42$ to $F-(n=3)$ and $\mathrm{D}-(n=4)$ connections. After washout for $10-30 \mathrm{~min}$., the failure rate are

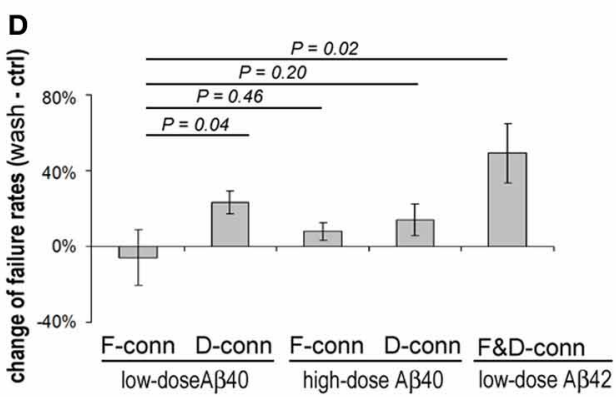

further exacerbated in applications of low-dose $A \beta 42$ to $F$ - and D-connections (compared with pre-application, $P=0.04$; compared with $A \beta$ application, $P=0.05)$. Note: ${ }^{*}$ compared with pre-application, ${ }^{\Delta}$ compared with $A \beta$ application; ${ }^{*}$ or $\Delta P<0.05$; ${ }^{* *} P<0.01$. (C) Net changes in average failure rates following exposure to $A \beta$ (the failure rate in $A \beta$ application - the failure rate in pre-application). The net rate change in low-dose $A \beta 40$ to F-connections was opposite in direction to that of the other cases. The difference between the net rate changes corresponding to low-dose $A \beta 40$ vs. high-dose $A \beta 40$ to F-connections did not quite reach statistically significance possibly due to the low $n(n=3)$ in the latter case. (D) Net changes to average failure rates by washout of $A \beta$ (the failure rate in washout of $A \beta$ - the failure rate in pre-application). The differential change in failure rates remained virtually similar to that in (C). Notably, the net rate change became smaller (from 41 to $14 \%$ ) in high-dose A $A 40$ to F-connection, but became bigger (from 21 to $49 \%$ ) in the cased of low-dose A 42 to F-and D-connections. synaptic parameters-AUDF (Markram et al., 1998; Tsodyks and Markram, 1997; Wang et al., 2006). Dynamic synaptic responses are due to the interplay between $U, D$, and $F$. $U$ represents the probability of synaptic transmitter release, $p . D$ is the time constant to recover from synaptic depression; $F$ is the time constant to recover from synaptic facilitation. The absolute strength, $A$, of a synaptic connection is defined as the maximum synaptic response when $p$ equals 1 . This approach is based on the mean output behavior of synaptic connections and therefore requires analyzing only average responses (Figure 3 upper row graphs). Fitting average responses of an EPSP train into the model yields values for AUDF parameters of a synaptic connection (Figure A2 and Table A1) (Tsodyks and Markram, 1997). According to the principle as verified in our previous studies (Tsodyks and Markram, 1997; Markram et al., 1998; Wang et al., 2006), changes in the synaptic parameters AUDF are essentially evaluated based on the amplitudes and the amplitude pattern of average EPSP train and RTR. Generally speaking, in the case of $A$ reduction, amplitudes of all EPSPs become smaller but the EPSP pattern remain unchanged. In the case of $U$ reduction, the amplitude of 1st EPSP is reduced while subsequent EPSPs, but not RTR, are facilitated. In the case of $D$ 
A

Low-dose $A \beta 40$

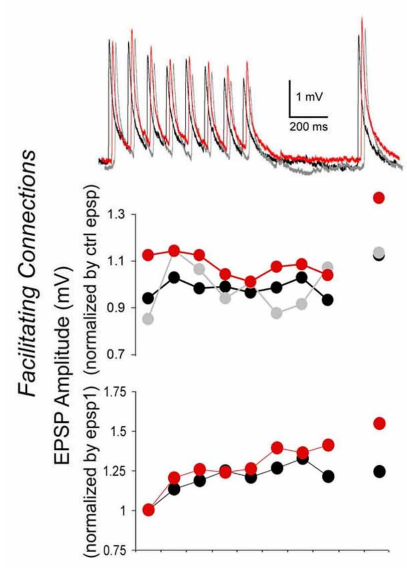

B

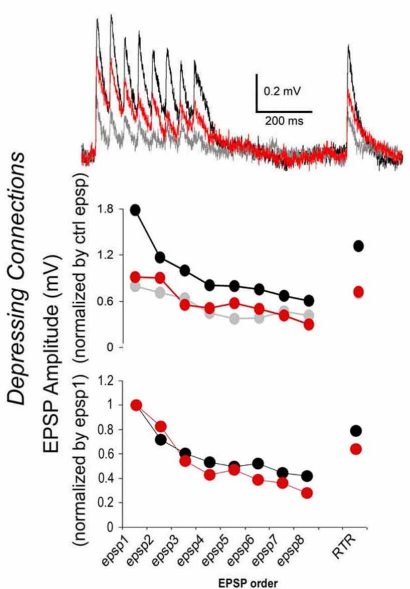

C High-dose $A \beta 40$

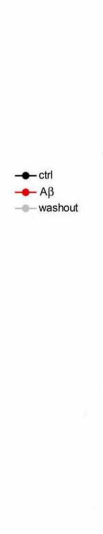

D
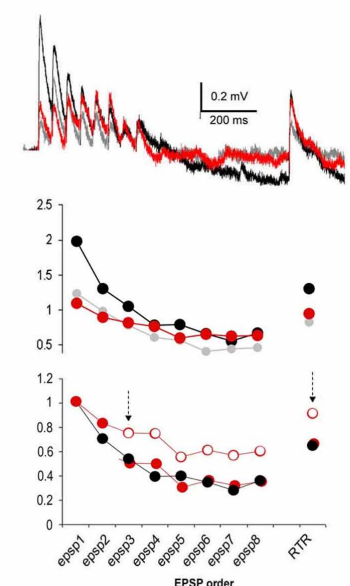

E

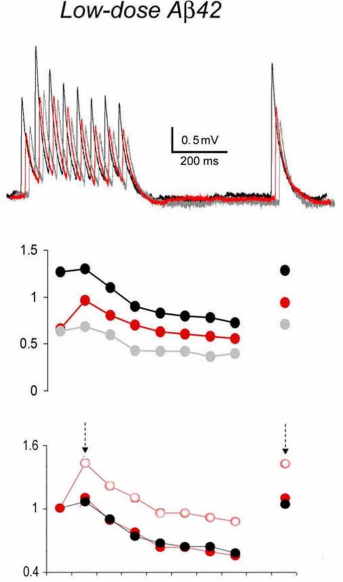

$\mathbf{F}$
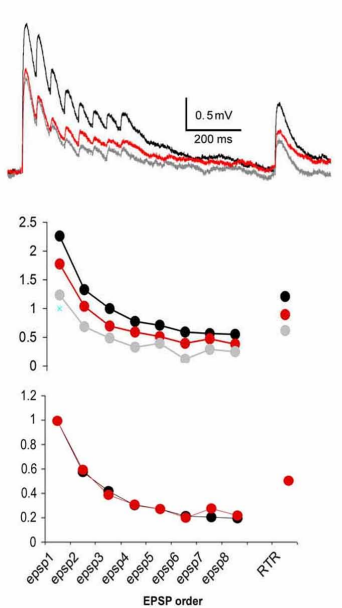

FIGURE 3 | EPSP trains of F- and D- connections change differentially depending upon the synapse type and the $A \beta$ species and

concentration. In each case, representative traces (each was an average of $15-30$ individual traces) from pre-application, $A \beta$ application and washout phases are presented at the top of each graph. The chart in the middle gives average EPSP amplitudes that were normalized to the mean of pre-application EPSPs for the comparison between pre-application and A $\beta$ application and washout. The chart at the bottom alternatively shows average EPSP amplitudes that were normalized instead to the 1st EPSP of their intrinsic run in order to access changes in EPSP patterns (for clarity, traces of washout were not plotted). (A) Low-dose A $\beta 40$ enhanced F-connections. The overall increase in the EPSP train was followed by a comparably larger increment in the RTR. The enhancement tended toward recovery after washout. (B) Low-dose A 440 inhibited D-connections. The EPSP amplitudes were all significantly diminished while the EPSP pattern remained virtually similar to that in pre-application. (C) High-dose A $\beta 40$ inhibited F-connections. EPSPs were unevenly reduced, in which the decrement of the 1st EPSP was greater. In the chart at the bottom, the empty circles between two arrows showed the real pattern of subsequent EPSPs as they relate to the 1st EPSP.
The red dots between two arrows that were disassociated with the 1st EPSPs, show a match up of patterns of subsequent EPSPs and RTR between pre-application and $A \beta$ application conditions. (D) High-dose A $\beta 40$ inhibited D-connections. The 1st EPSP was notably reduced while the amplitudes of steady state EPSPs (4th through 8th EPSPs) remained unchanged, followed by a reduced RTR. Between two arrows in the chart at the bottom, the empty circles show the pattern of 3rd through 8th EPSPs + RTR as they relate to the 1st and 2nd EPSPs, and the red dots between two arrows were disassociated with the 1st and 2nd EPSPs, giving the matching patterns of 3rd-8th EPSPs and RTR between pre-application and A $\beta$ applications. (E) Low-dose AB42 inhibited F-connections. EPSPs were unevenly reduced, also indicating that the decrement of the 1st EPSP was greater (The same chart presentation was made as in C). (F) Low-dose A 42 inhibited D-connections. EPSPs were all significantly diminished while the EPSP pattern remained almost the same as in pre-application. Note: Upon washout of $A \beta$ (see the middle charts, also see Table 1), the enhancement of low-dose A $\beta 40$ to F-connections (in $\mathbf{A}$ ) appeared to recover to the pre-application level while EPSPs inhibited by A $\beta$ did not recover in $\mathbf{B}-\mathbf{D}$ or even further diminished in $\mathbf{E}$ and $\mathbf{F}$. enhancement, both subsequent EPSPs and RTR are reduced. In the case of $F$ enhancement, both subsequent EPSPs and RTR are increased.

In accordance to this model (Tsodyks and Markram, 1997; Markram et al., 1998; Wang et al., 2006), EPSP trains evoked by 5-8 presynaptic APs and a RTR recorded after a $500 \mathrm{~ms}$ delay were analyzed for the estimation of synaptic dynamics based on their amplitudes and patterns of EPSPs, respectively, in pre-application, various $A \beta$ application and washout conditions (Figure 3). For comparison between pre-application and $A \beta$ 
Table 1 | Comparison results of EPSP trains recorded in pre-application, application and washout of A $\beta$.

\begin{tabular}{|c|c|c|c|c|c|c|}
\hline & \multicolumn{2}{|c|}{ low-dose $A \beta 40$} & \multicolumn{2}{|c|}{ high-dose $A \beta 40$ and $A \beta 25-35$} & \multicolumn{2}{|c|}{ low-dose Aß42 } \\
\hline & F-connection & D-connection & F-connection & D-connection & F-connection & D-connection \\
\hline ctrl vs. $A \beta$ & $P=0.02$ & $P<0.001$ & $P<0.001$ & $P<0.001$ & $P<0.001$ & $P<0.001$ \\
\hline ctrl vs. washout & $P=0.96$ & $P<0.001$ & $P<0.001$ & $P<0.001$ & $P<0.001$ & $P<0.001$ \\
\hline
\end{tabular}

Paired student t-test was used with multiple outcome values per connection.

application and washout, average EPSP amplitudes of individual synaptic connections were first normalized to the mean of EPSPs in pre-application conditions (Figure 3 middle row graphs) of either low dose $\mathrm{A} \beta 40$ (Figures $\mathbf{3 A}, \mathbf{B}$ ) or high dose $\mathrm{A} \beta 40$ (Figures 3C,D) or low dose $\mathrm{A} \beta 42$ (Figures 3E,F) applications, respectively. Next, in order to better present changes in EPSP patterns, the same responses were alternatively normalized to the 1st EPSP of their own trains (Figure 3 lower row graphs).

Compared with the pre-application, EPSP amplitudes were significantly increased in F-connections exposed to low-dose $\mathrm{A} \beta 40$ (Figure 3A, $n=12$ pairs). The amplitude increase of the EPSP train was followed by a comparably larger increment in the RTR (Figure 3A lower row graph), which indicated the enhanced facilitation, $F$. In all other conditions examined (low-dose A $\beta 40$ to D-connections, high-dose $\mathrm{A} \beta 40$ to $\mathrm{F}$ - or D-connections and low-dose A $\beta 42$ to F- or D-connections) (Figures 3B-F), the EPSP amplitudes were all significantly diminished compared to their own pre-applications, respectively, (Table 1). In both low-dose $\mathrm{A} \beta 40$ and low-dose $\mathrm{A} \beta 42$ to D-connections (Figure 3B, $n=7$ pairs; Figure 3F, $n=5$ pairs), the amplitudes of EPSPs were evenly reduced and the EPSP pattern virtually remained the same as in the pre-application. This change is represented as a typical reduction in the absolute synaptic strength, $A$. Interestingly, highdose $\mathrm{A} \beta 40$ and low-dose $\mathrm{A} \beta 42$ in F-type connections (Figure 3C, $n=4$ pairs; Figure $3 \mathrm{E}, n=8$ pairs) similarly resulted in an uneven reduction of EPSP trains and RTR, in which the decrements of the 1st EPSPs were greater. This result indicated a reduction in absolute synaptic strength, $A$ (according to a decline in all EPSPs) accompanied by a reduced release probability, $U$ (according to the greater decrements of the 1st EPSPs). In the high-dose $\mathrm{A} \beta 40$ to $\mathrm{D}$-connections (Figure $3 \mathrm{D}, n=7$ pairs), the 1 st EPSP was notably reduced while the amplitudes of steady state EPSPs (4th-8th EPSPs) remained unchanged. The notable decrement of the 1st EPSP represented a $U$ reduction, which typically leads to an immediate facilitation of subsequent EPSPs of the train. However, such an immediate facilitation was not visible. Instead, the unchanged steady state EPSPs was followed by a reduced RTR. This phenomenon could be attributed to an interplay of the reduction in both $U$ and $A$. The immediate facilitation of subsequent EPSPs due to the notable $U$ reduction, would counterbalance the reduction of these EPSPs due to the reduction of parameter $A$, keeping them unchanged.

High-dose A $\beta 25-35$ was used in a few test recordings considering the fact that this short peptide has neurotoxic action and aggregating property (Chen et al., 2000). The high-dose A $\beta 25-35$ showed inhibiting effects on EPSP trains of F- $(n=2$ pairs $)$ and
D-connections ( $n=3$ pairs). The changes in EPSP train induced by $A \beta 25-35$ were similar to those induced by the high-dose $\mathrm{A} \beta 40$.

\section{EFFECTS OF A $\beta$ ARE FULLY REVERSIBLE WHEN APPLIED BRIEFLY AND LOCALLY}

It is noteworthy that upon washout of the various $A \beta$-containing mediums, only the enhancement of F-connections by low-dose A $\beta 40$ recovered $(P>0.05$ in Table 1, Figure 3$)$. The reductions in EPSP train and RTR in all the other cases did not $(P<0.05$ in Table 1). Rather than reflecting inefficient washout, we suspect a damaging effect on synapses was induced by prolonged $\mathrm{A} \beta$ conditions such as in the presence of high concentrations of $\mathrm{A} \beta 40$ or low-dose $\mathrm{A} \beta 42$. To test this, we briefly applied 1nM A $\beta 42$ $(n=2)$ or $1 \mu \mathrm{M} \mathrm{A} \beta 40(n=1)$ locally to a synaptic connection via a "puff" using a 3rd pipette (a representative recording is shown in Figure 4, estimating that the local concentration of $A \beta$ remained close to the concentration in the pipette). Recordings were obtained prior to and at the end of peptide application (only $2 \mathrm{~min}$ ) and bath washout phases $(10 \mathrm{~min})$. The synaptic

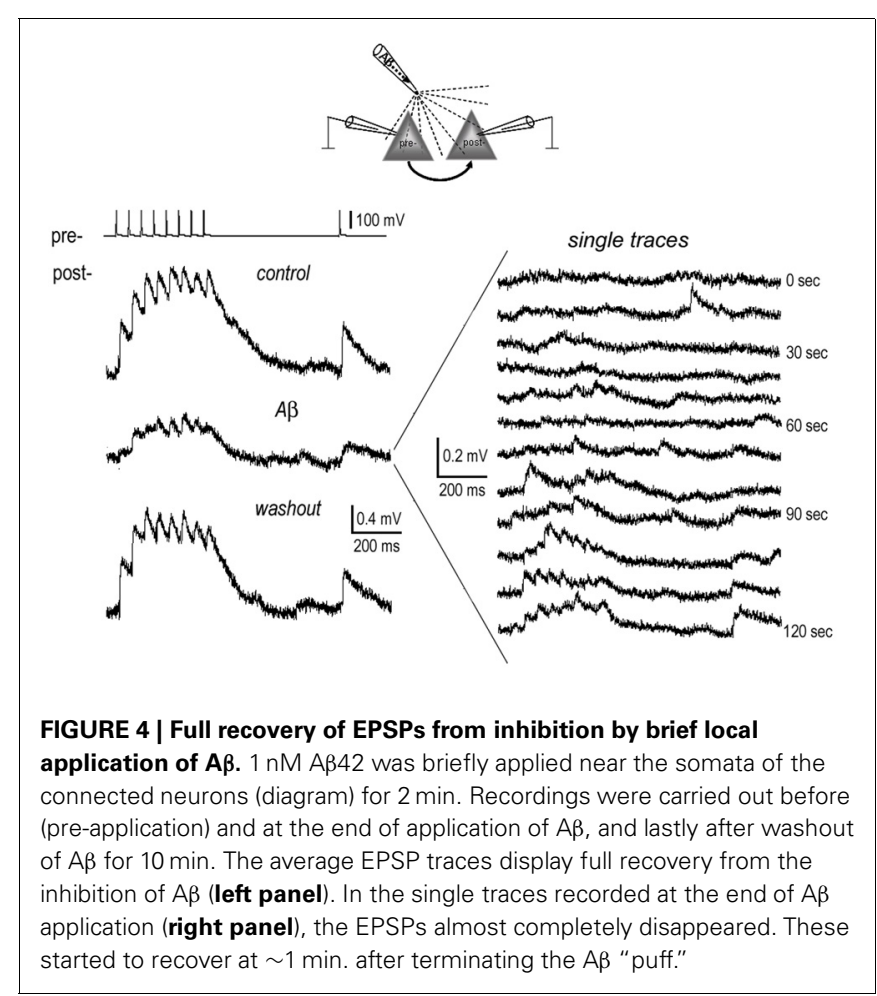


responses almost completely disappeared at the end of application of $\mathrm{A} \beta$. The recovery of EPSPs, however, began quickly at $\sim 1$ min after the application phase of $\mathrm{A} \beta$ had terminated and was largely recovering from inhibition within $2 \mathrm{~min}$ into the washout (Figure 4, right panel). A full recovery was observed $10 \mathrm{~min}$ into the washout (Figure 4, the bottom trace in left panel). These results suggest that brief, highly local exposures of synapses to $\mathrm{A} \beta$ (even at a high level of concentration) produce reversible inhibition. With this evidence, the aforementioned irreversible inhibitory effects of bath-applied peptides becomes understandable if either modest diffuse accumulations of $A \beta 42$ or abnormally high levels of $A \beta 40$, may be enough to damage synapse function.

\section{OPPOSITE EFFECTS OF LOW NANOMOLAR A 340 AND Aß42 ON SHORT TERM POTENTIATION OF F-CONNECTIONS}

In the excitatory neuronal network of the PFC, the F-type connections prominently exhibit forms of short term potentiation
(STP) termed SA and PTP (Wang et al., 2006). We next examined effects of low-dose $A \beta 40$ and $A \beta 42$ on the SA and PTP in Fconnections. Compared with pre-application, the low-dose $A \beta 40$ to F-connections significantly enhanced synaptic responses during all recording phases, i.e., pre-tetanus baseline, SA induction and PTP induction (Figure 5A1, paired $t$-test with multiple outcome values per connection: all $P<0.01, n=4$ connected pairs). After washout for 10-30 min, the pre-tetanus EPSPs recovered $(P=0.557)$, however, the enhanced EPSPs still remained at a significantly higher level during the SA and PTP phases (Figure 5A1 inset table, both $P<0.01)$. Thus, on average, the low-dose $\mathrm{A} \beta 40$ enhanced pre-tetanus EPSP by $23 \pm 6 \%$ (Figure 5A2, $P=0.01)$, which recovered after washout for $10-30 \mathrm{~min}(P=$ 0.556). Meanwhile, the induction of SA was enhanced nearly 2-fold by the low-dose $A \beta 40(30 \pm 13 \%$ vs. $16 \pm 9 \%$ in preapplication, $P=0.141$ ) and the enhancement to nearly 4 -fold persisted after washout for $10-30 \mathrm{~min}(58 \pm 16 \%$ vs. $16 \pm$ $9 \%, P=0.05)$. Similarly, the induction of PTP was enhanced

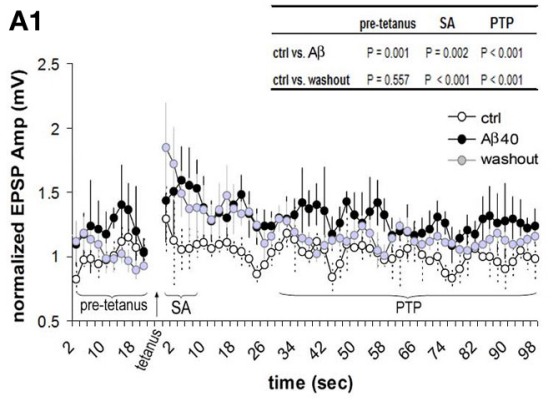

A2

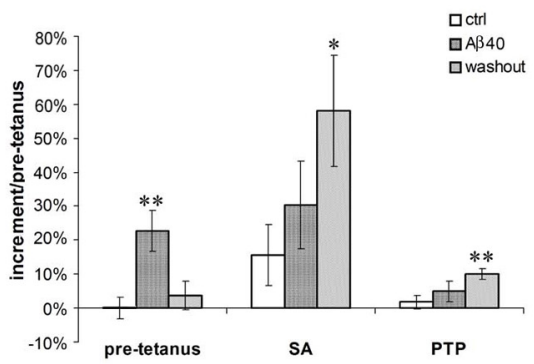

FIGURE 5 | Differential effects of low nanomolar $A \beta 40$ and $A \beta 42$ on the SA and PTP. (A1) Low-dose AB40 enhanced synaptic responses (i.e., EPSPS) under all the recording phases (pre-tetanus baseline, SA induction and PTP induction) in F-connections (all $P<0.01, n=4$ pairs). After washout for 10-30 min, the EPSPs during the pre-tetanus phase recovered to the pre-application level $(P=0.557)$, but still remained significantly higher during the SA and PTP induction phases (both $P<0.01$, inset table). EPSP amplitudes were normalized to the mean of pre-tetanus EPSPs in pre-application. Paired $t$-test with multiple outcome values per connection was performed between pre-application and $A \beta$ application, and between pre-application and washout phases. (A2) Comparison of increments during pre-tetanus, SA and PTP induction in the case of low-dose A 340 application. Compared with the baseline level $(0 \pm 3 \%)$ of increment during pre-tetanus phase of pre-application condition, low-dose $A \beta 40$ enhanced the average baseline EPSP by $23 \pm 6 \%(P=0.01)$, recovering after a 10-30 min washout ( $4 \pm 4 \%, P=0.556)$. Compared with $16 \pm 9 \%$ in pre-application, the $S A$ appeared to be enhanced by low-dose $A \beta 40$ to $30 \% \pm 13 \%(P=0.141)$, and remained enhanced at an average level of $58 \pm 16 \%$ after a $10-30 \mathrm{~min}$.

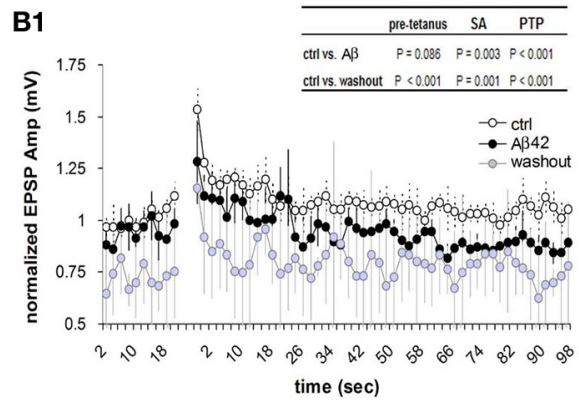

B2

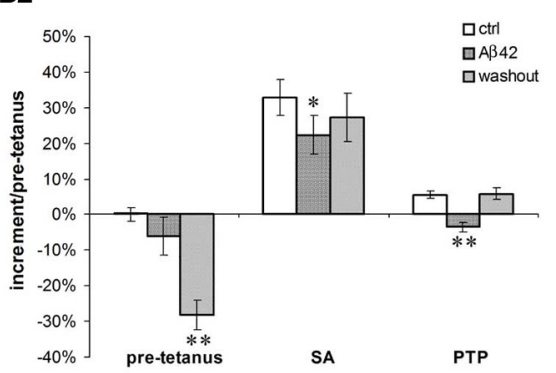

washout $(P=0.05)$. Similarly, compared with $2 \pm 2 \%$ in pre-application condition, the PTP appeared to be enhanced by low-dose A $\beta 40$ to $5 \pm 3 \%$ $(P=0.284)$, and remained enhanced to a statistically significant level after a 10-30 min. washout (10 $\pm 2 \%, P=0.01)$. (B1) Low-dose A $\beta 42$ depressed synaptic responses at the pre-tetanus baseline, and significantly at the SA and PTP inductions (both $P<0.01, n=6$ pairs). After a $10-30 \mathrm{~min}$. washout, the EPSPs under all the recording phases (pre-tetanus, SA induction and PTP induction) became significantly depressed ( $P<0.01$, inset table). (B2) Comparison of increments during pre-tetanus, SA and PTP inductions in low-dose A $\beta 42$ applications. Compared with the baseline level $(0 \pm 2 \%)$ of increment during the pre-tetanus phase of pre-application condition, low-dose A 442 depressed the average baseline EPSP by $-6 \pm 5 \%(P=0.08)$. This became statistically significant after washout $(-28 \pm 4 \%, P<0.01)$. Compared with $33 \pm 5 \%$ in pre-application, the SA was significantly depressed by low-dose $A \beta 42$ to $22 \pm 5 \%(P=0.01)$, recovering after washout $(27 \pm 7 \%$, $P=0.530)$. Compared with $6 \pm 1 \%$ of the increment in pre-application, the PTP was significantly depressed by low-dose $A \beta 42$ to $-4 \pm 1 \%(P=0.01)$, again recovering after washout $(6 \pm 2 \%, P=0.154) .{ }^{*} P<0.05 ; * * P<0.01$. 
more than 2-fold by the low-dose $A \beta 40$ ( $5 \pm 3 \%$ vs. $2 \pm 2 \%$ in pre-application, $P=0.284)$ and the enhancement to 5 -fold persisted after washout $(10 \pm 2 \%$ vs. $2 \pm 2 \%, P<0.01)$. In the comparison, the borderline absence of statistical significance was likely due to the low sampling of these difficult-to-obtain recordings.

In contrast, low-dose A $\beta 42$ significantly depressed synaptic responses corresponding to the SA and PTP inductions (Figure 5B1, both $P<0.01, n=6$ connected pairs). After washout for 10-30 min, the EPSPs comprising the SA and PTP phases of STP were further depressed (both $P<0.01$ ). Meanwhile, the EPSPs of the pre-tetanus baseline were also significantly depressed (Figure 5B1 inset table, $P<0.01$ ). In Figure 5B2, the opposing actions of low-dose $A \beta 42$ highly contrast the actions of low-dose $A \beta 40$ in Figure 5A2. Compared with the pre-tetanus baseline level in pre-application $(0 \pm 2 \%)$, the average EPSP during pre-tetanus recordings became progressively depressed into the recording procedure beginning with the application of low-dose $\mathrm{A} \beta 42$ and into washout (depressed by $-6 \pm 5 \%, P=0.08$ and by $-28 \pm 4 \%, P<0.01$, respectively). The average EPSP increment of SA was originally $33 \pm 5 \%$ in pre- $A \beta$ application. This was significantly reduced to $22 \pm 5 \%$ following bath application of low-dose $A \beta 42(P=0.05)$. The average EPSP increment of PTP was $6 \pm 1 \%$ in pre-application, which became depressed to $-4 \pm 1 \%$ after low-dose $A \beta 42$ was bath applied $(P<0.01)$. Taken together, effects of low nanomolar concentrations of $\mathrm{A} \beta 40$ and $\mathrm{A} \beta 42$ on EPSP amplitudes are already opposite each other in the pre-tetanus condition, presaging their beneficial and depressing effects on SA and PTP, respectively. These actions on STP induction match their aforementioned influences on isolated EPSP failure rates and on EPSP trains.

\section{DISCUSSION}

The experiments in the current study have explored the effects of soluble monomer predominant extracellular $\mathrm{A} \beta$ peptides on synaptic failure rates, synaptic dynamic properties and STP (including SA and PTP) of single excitatory connections in normal PFC. The PFC is highly vulnerable to the effects of aging and neurodegeneration but is relatively understudied in AD. To our knowledge, these are the first whole-cell patch clamp recordings from pairs of individual connections formed by pyramidal neurons in PFC that examine $A \beta$ modulation and toxicity on chemical synaptic transmissions. The advantage of this technique over more conventional field studies is that influences from other afferents and reverberant circuits and influences by exciting neuromodulatory fibers are virtually avoided. In addition, the results are highly repeatable based on single synaptic connections that are classified according to their unitary synaptic dynamics.

We found that the transmission involving individual synaptic connections was significantly enhanced or reduced depending on their intrinsic type (facilitating or depressing), the tested $\mathrm{A} \beta$ species (40 or 42 amino acids) and concentration (low dose 1-200 nM vs. high dose 0.3-1 $\mu \mathrm{M}$ ). Our main findings are that bath applications of low nanomolar $\mathrm{A} \beta 40$ have opposite actions on basal and STP properties of
F-connections compared with high nanomolar $A \beta 40$ or low nanomolar $A \beta 42$. Specifically, when applied to F-connections, low nanomolar $A \beta 40$ reduces failure rate and enhances EPSP trains and SA and PTP, whereas higher nanomolar A 340 and low nanomolar $A \beta 42$ alike inhibit them. Interestingly, low nanomolar $\mathrm{A} \beta 40$ inhibits $\mathrm{D}$-connections, acting similarly thereon as high nanomolar $A \beta 40$ or low nanomolar $A \beta 42$. In addition, the inhibitory effects of these bath-applied peptides often appeared irreversible despite long-time washout. Nevertheless, reversibility could be demonstrated when $A \beta$ was applied very locally, briefly and followed with a thorough washout.

Normal concentrations of $\mathrm{A} \beta$ in CSF and plasma are in the picomolar range (Bohrmann et al., 1999; Teunissen et al., 2002; Lewczuk et al., 2004), but likely higher in the synaptic cleft. Our differential results in the nanomolar range may add new insight into the modulatory role of $\mathrm{A} \beta 40$ by balancing facilitation and depression of synaptic connections to influence activity of synaptic networks in the PFC. Specifically, A $\beta 40$ at physiological levels moderately reduced EPSP failure rate and significantly enhanced EPSP trains and STP of F-connections while dampening D-connections. The net functional result would be to enhance network activity relevant to working memory while limiting incoming distracting signals, respectively. The first study to show that A $\beta 40$ actually increased LTP was Wu et al. (1995), moreover the effect was noticed at $200 \mathrm{nM}$, same as our "low dose" upper limit. In addition, our results add to the notion from other work that $A \beta 40$ could actually have a beneficial role to moderate $A \beta 42$ effects (Kim et al., 2007). They are also in line with the differential effects of $A \beta 42$ and $A \beta 25-35$ peptides on hippocampal network activation, specifically on $\theta$, $\beta$, and $\gamma$ oscillations (Adaya-Villanueva et al., 2010). However, the possibility is not excluded that $\mathrm{A} \beta 42$ at much lower levels such as in the picomolar range also plays a similar physiological role as does $A \beta 40$ in synaptic modulation. In a former study of recordings from hippocampal slices, low picomolar concentrations of $\mathrm{A} \beta 42$ caused a marked increase of long-term potentiation in excitatory cells, whereas high nanomolar concentrations lead to the reduction of the potentiation (Puzzo et al., 2008). It may be necessary to study the effects of picomolar $A \beta 42$ on single synaptic connections in future experiments.

In recent years, it has been found that $A \beta$ is physiologically released from synaptic terminals depending on the levels of synaptic activity (Kamenetz et al., 2003; Cirrito et al., 2005). In turn, $A \beta$ may play an inhibitory feedback role to balance the homeostatsis of neuronal networks (Kamenetz et al., 2003; Hsieh et al., 2006; Venkitaramani et al., 2007). A feature of this feedback loop is that $\mathrm{A} \beta$ peptides are eventually cleared by endocytosis and diffusion (Venkitaramani et al., 2007). Our results imply that $A \beta 40$ at high nanomolar concentrations or $\mathrm{A} \beta 42$ at concentrations as studied here induced an inhibition that might serve as feedback to limit synaptic activity and $A \beta$ production. This is supported by our observation that inhibition of synaptic responses fully recovers when $A \beta$ (40 or 42) is applied briefly and locally followed by a prompt washout (which may be closer to the physiological processes 
of endocytosis and diffusion). Conversely, inhibition becomes more difficult to recover from after longer-time bath applications of these peptides. These considerations make it likely that the toxic effects of these peptides on synaptic functions become irreversible once they accumulate near synapses to concentrations that overload endocytic and enzymatic removal mechanisms.

The potential toxicity to synaptic function as evidenced by the resistance to recovery following washout could result from the formation of aggregated $A \beta$ oligomers around synapses aided by long bath application times and high concentrations. The $A \beta$ aggregation is dependent on protein concentration and time (Harper and Lansbury, 1997). Aggregated A $\beta$ oligomers may suppress synaptic responses by disrupting synaptic vesicle endocytosis (Kelly and Ferreira, 2007), inhibiting NMDA receptors (Chen et al., 2002) and P/Q-type calcium currents (Nimmrich et al., 2008) and/or via forming artificial ion pores on neuronal membranes (Small et al., 2009). A $\beta 40$ on the other hand may enhance synaptic facilitation by acting on P-type calcium channels, but once forming oligomers appears to lose the facilitating effect, turning to suppressing synaptic functions (Ramsden et al., 2002). This could explain the opposite effects of $\mathrm{A} \beta 40$ at low vs. high concentrations as observed in the current study. Since $A \beta 42$ aggregates more readily than the other $A \beta$ species (Snyder et al., 1994), it is not surprising that $A \beta 42$ might only enhance synaptic activity at picomolar levels (Puzzo et al., 2008). Otherwise, A $\beta 42$ induces synaptic depression at concentrations at or above the low nanomolar range. In recent years, several studies reported that extrasynaptic NMDA receptors are activated by $\mathrm{A} \beta$ oligomers, leading to synaptic dysfunction. Soluble $A \beta$ oligomers increase activation of extrasynaptic NR2B receptors inhibiting NMDAR-dependent LTP (Li et al., 2011). $\mathrm{A} \beta$ oligomers also reduce baseline synaptic transmission and spontaneous neuronal network activity and induce retraction of synaptic contacts (Ronicke et al., 2011), some of which may be dependent on extrasynaptic sites of action. Prolonged activation of extrasynaptic NMDAR by $\mathrm{A} \beta$ oligomers may also play a key role in pathogenic mechanisms of glutamate excitotoxicity (Stanika et al., 2009), and cell death (Hardingham et al., 2002; Papadia and Hardingham, 2007). While our results pertain to synaptic dysfunction at the resolution of single synaptic connections, future studies are foreseeable to address any extrasynaptic contributions.

An important factor to consider is whether such effects of $A \beta$ peptides on synaptic transmission and plasticity occur at the preor post-synaptic element. With our research scheme, this can be speculated upon according to changes in the synaptic dynamic parameters, $D-F-U-A$. The enhancement to F-connections by low-dose $\mathrm{A} \beta 40$ occurs via an increase in the parameter $F$, a presynaptic mechanism. This is further supported by the enhancement to the SA and PTP by the low-dose A $\beta 40$. It is well-known that synaptic facilitation is mediated by presynaptic residual calcium (Kamiya and Zucker, 1994; Mongillo et al., 2008) and the induction of SA and PTP relies on pre-synaptic mechanisms (Hempel et al., 2000; Zucker and Regehr, 2002). It has also been reported that $A \beta$ acts via presynaptic mechanisms as a positive endogenous modulator for hippocampal synapses in rodent hippocampal cultures and slices (Abramov et al., 2009). The enhancement of F-connections we observe could therefore be related to an effect of $A \beta 40$ acting on P-type calcium channels, a pre-synaptic calcium channel that mediates synaptic facilitation (Ramsden et al., 2002; Tamse et al., 2003; Iegorova et al., 2010). Both low-dose $A \beta 40$ and $A \beta 42$ inhibit D-connections via reducing synaptic strength, reflected in parameter $A$. The $A$ parameter represents the synaptic response when the probability of synaptic transmitter release equals 1 at the maximal level. Therefore, changes in synaptic strength, $A$, basically represents alterations in the postsynaptic elements. High-dose A $\beta 40$ inhibits both $\mathrm{F}$ - and $\mathrm{D}$-connections via reducing the release probability, $U$, and the synaptic strength, $A$, which involves both preand post-synaptic mechanisms. With respect to the same mechanisms, low-dose A $\beta 42$ inhibits F-connections. Experimentally, an inhibition on presynaptic transmission is reported after $\mathrm{A} \beta 42$ injection through a block of vesicle fusion in the terminal (Moreno et al., 2009), and the inhibition by $\mathrm{A} \beta$ on postsynaptic sites has previously been verified to occur at multiple molecular structures such as AMPA receptors and metabotropic glutamate receptors (Puchtler and Sweat, 1962; Wang et al., 2004; Hsieh et al., 2006; Shemer et al., 2006; Minano-Molina et al., 2011).

Acting on both pre- and post-synaptic sites, $\mathrm{A} \beta$ peptides are likely to have multiple actions on multi-synaptic activity in neuronal networks. Low nanomolar concentrations of $A \beta 40$ significantly enhance synaptic facilitation and both SA and PTP forms of STP of F-connections, meanwhile, inhibiting the synaptic strength $(A)$ of D-connections. This finding suggests that $\mathrm{A} \beta 40$ differentially enhances $\mathrm{F}$-connections via presynaptic sites and inhibits $\mathrm{D}$-connections via postsynaptic sites. High nanomolar $\mathrm{A} \beta 40$, on the other hand, inhibits both F- and Dconnections through reductions in both $U$ and $A$ parameters. $\mathrm{A} \beta 42$, even at low nanomolar concentrations, inhibits not only $\mathrm{D}$-connections by reducing $A$, but also to F-connections by reducing both $U$ and $A$. These peptides at relatively higher concentrations are therefore expected to play a physiological negative feedback role and/or to produce toxic effects on synaptic functions via both pre- and post-synaptic mechanisms. In addition to pre- and post- synaptic regulation of synaptic activity by physiological levels of $A \beta$ and the depression of excitatory transmission by pathological levels, $A \beta$ peptides are also shown to trigger aberrant synchronous circuit activity, even epileptic discharges, at the network level (Minkeviciene et al., 2009; Palop and Mucke, 2010). Our previous work shows that high levels of soluble $\mathrm{A} \beta$ may be involved in aberrant synchronous circuit activity via enhancing neuronal excitability and acting on electrical networks. Here again, physiological levels of $\mathrm{A} \beta$ act oppositely playing a negative feedback role to dampen electrical network activity by reducing neuronal excitability (Wang et al., 2009). Future patch clamp recording of inhibitory synaptic connections formed between interneuron and PC pairs can further address this issue from another point of view. 
The PFC network has the capacity to support persistent activities during recurrent weak inputs, without resorting to the metabolic expenditure of AP generation, precisely because of some special built-in functions such as synaptic facilitation and predominant STP (Hempel et al., 2000; Wang et al., 2006; Mongillo et al., 2008). Facilitation lasting hundreds of milliseconds (and outlasting depression), SA lasting up to $10 \mathrm{~s}$, and PTP lasting up to minutes are each likely to be important mechanisms to sustain network activity during short-term storage and manipulation processes such as working memory tasks (Magleby, 1987; Fisher et al., 1997; Mongillo et al., 2008). STP is an especially important correlate in the PFC to its integrative functions of working memory as well as in the organization of sequential behavior, mental flexibility and planning (Grafman, 1995; Hempel et al., 2000; Mongillo et al., 2008). Understanding endogenous modulators of the working memory network and its processes is increasingly important to the cognition and neurodegeneration fields. At the

\section{REFERENCES}

Abramov, E., Dolev, I., Fogel, H., Ciccotosto, G. D., Ruff, E., and Slutsky, I. (2009). Amyloid-beta as a positive endogenous regulator of release probability at hippocampal synapses. Nat. Neurosci. 12, 1567-1576. doi: 10.1038/nn.2433

Adaya-Villanueva, A., Ordaz, B., Balleza-Tapia, H., MarquezRamos, A., and Pena-Ortega, F. (2010). Beta-like hippocampal network activity is differentially affected by amyloid beta peptides. Peptides 31, 1761-1766. doi: 10.1016/j.peptides.2010.06.003

Arendt, T. (2001). Disturbance of neuronal plasticity is a critical pathogenetic event in Alzheimer's disease. Int. J. Dev. Neurosci. 19, 231-245. doi: $\quad 10.1016 / \mathrm{S} 0736-5748(01)$ 00007-7

Bohrmann, B., Tjernberg, L., Kuner, P., Poli, S., Levet-Trafit, B., Naslund, J., et al. (1999). Endogenous proteins controlling amyloid beta-peptide polymerization. Possible implications for beta-amyloid formation in the central nervous system and in peripheral tissues. J. Biol. Chem. 274, 15990-15995. doi: 10.1074/jbc.274.23.15990

Chen, Q. S., Kagan, B. L., Hirakura, Y., and Xie, C. W. (2000). Impairment of hippocampal long-term potentiation by Alzheimer amyloid betapeptides. J. Neurosci. Res. 60, 65-72.

Chen, Q. S., Wei, W. Z., Shimahara, T., and Xie, C. W. (2002). Alzheimer amyloid beta-peptide inhibits the late phase of long-term potentiation through calcineurin-dependent mechanisms in the hippocampal dentate gyrus. Neurobiol.
Learn. Mem. 77, 354-371. doi: 10.1006/nlme.2001.4034

Cirrito, J. R., Yamada, K. A., Finn, M. B., Sloviter, R. S., Bales, K. R., May, P. C., et al. (2005). Synaptic activity regulates interstitial fluid amyloid-beta levels in vivo. Neuron 48, 913-922. doi: 10.1016/j.neuron.2005.10.028

Davies, C. A., Mann, D. M., Sumpter, P. Q., and Yates, P. O. (1987). A quantitative morphometric analysis of the neuronal and synaptic content of the frontal and temporal cortex in patients with Alzheimer's dis10.1016/0022-510X(87)90057-8

Dodart, J. C., Mathis, C., Bales, K. R., and Paul, S. M. (2002). Does my mouse have Alzheimer's disease. Genes Brain Behav. 1, 142-155. doi: 10.1034/j.1601-183X.2002.10302.x

Esteban, J. A. (2004). Living with the enemy: a physiological role for the beta-amyloid peptide. Trends Neurosci. 27, 1-3. doi: 10.1016/j.tins.2003.10.008

Fisher, S. A., Fischer, T. M., and Carew, T. J. (1997). Multiple overlapping processes underlying short-term synaptic enhancement. Trends Neurosci. 20, 170-177. doi: 10.1016/S0166-2236(96)01001-6

Goldman-Rakic, P. S. (1995). Cellular basis of working memory. Neuron 14, 477-485. doi: 10.1016/08966273(95)90304-6

Goldman-Rakic, P. S. (1996). Regional and cellular fractionation of working memory. Proc. Natl. Acad. Sci. U.S.A. 93, 13473-13480. doi: 10.1073/pnas.93.24.13473 Vincent, B., Edgar, M., Checler, F., et al. (2000). Intraneuronal ease. J. Neurol. Sci. 78, 151-164. doi:

Gouras, G. K., Tsai, J., Naslund, J.,

resolution of single excitatory synaptic connections, our results show that $\mathrm{A} \beta$ may be a homeostatic modulator and play multiple roles depending on intrinsic synapse types, soluble $A \beta$ species and their levels in the synaptic environment. Thus, we predict that $A \beta$ influences persistent neuronal activity during working memory tasks in the PFC. High concentrations and mild accumulation of $A \beta$ around synapses likely lead to declines in memory and cognition such as in the early stages of $\mathrm{AD}$.

\section{ACKNOWLEDGMENTS}

This work was supported mainly by an Investigator Initiated Research Grant from Alzheimer's Association in USA (IIRG-0759954), also by a Natalie V. Zucker Research Center for Women Scholars from Tufts University School of Medicine in USA, and BBP/HBP from EPFL in Switzerland. These results were presented at the American Neurological Association meetings in 2010 .

Abeta42 accumulation in human brain. Am. J. Pathol. 156, 15-20. doi: 10.1016/S0002-9440(10)64700-1

Grafman, J. (1995). Similarities and distinctions among current models of prefrontal cortical functions. Ann. N.Y. Acad. Sci. 769, 337-368. doi: 10.1111/j.17496632.1995.tb38149.x

Hardingham, G. E., Fukunaga, Y., and Bading, H. (2002). Extrasynaptic NMDARs oppose synaptic NMDARs by triggering CREB shut-off and cell death pathways. Nat. Neurosci. 5, 405-414.

Harper, J. D., and Lansbury, P. T. Jr. (1997). Models of amyloid seeding in Alzheimer's disease and scrapie: mechanistic truths and physiological consequences of the time-dependent solubility of amyloid proteins. Annu. Rev. Biochem. 66, 385-407. doi: 10.1146/annurev.biochem. 66.1.385

Hempel, C. M., Hartman, K. H., Wang, X. J., Turrigiano, G. G., and Nelson, S. B. (2000). Multiple forms of short-term plasticity at excitatory synapses in rat medial prefrontal cortex. J. Neurophysiol. 83, 3031-3041.

Hsieh, H., Boehm, J., Sato, C. Iwatsubo, T., Tomita, T., Sisodia, S., et al. (2006). AMPAR removal underlies Abeta-induced synaptic depression and dendritic spine loss. Neuron 52, 831-843. doi: $\quad 10.1016 /$ j.neuron.2006. 10.035

Iegorova, O., Fisyunov, A., and Krishtal, O. (2010). G-proteinindependent modulation of P-type calcium channels by muopioids in Purkinje neurons of rat.
Neurosci. Lett. 480, 106-111. doi: 10.1016/j.neulet.2010.06.015

Kamenetz, F., Tomita, T., Hsieh, H., Seabrook, G., Borchelt, D., Iwatsubo, T., et al. (2003). APP processing and synaptic function. Neuron 37, 925-937. doi: 10.1016/S0896-6273(03)00124-7

Kamiya, H., and Zucker, R. S. (1994). Residual Ca2+ and short-term synaptic plasticity. Nature 371, 603-606. doi: 10.1038/ 371603a0

Kelly, B. L., and Ferreira, A. (2007). Beta-amyloid disrupted synaptic vesicle endocytosis in cultured hippocampal neurons. Neuroscience 147, 60-70. doi: 10.1016/j.neuroscience.2007.03.047

Kim, J., Onstead, L., Randle, S., Price, R., Smithson, L., Zwizinski, C., et al. (2007). Abeta40 inhibits amyloid deposition in vivo. J. Neurosci. 27, 627-633. doi: 10.1523/JNEUROSCI.4849-06.2007

Klyubin, I., Walsh, D. M., Lemere, C. A., Cullen, W. K., Shankar, G. M., Betts, V., et al. (2005). Amyloid beta protein immunotherapy neutralizes Abeta oligomers that disrupt synaptic plasticity in vivo. Nat. Med. 11 , 556-561. doi: 10.1038/nm1234

Lewczuk, P., Esselmann, H., Bibl, M., Paul, S., Svitek, J., Miertschischk J., et al. (2004). Electrophoretic separation of amyloid beta peptides in plasma. Electrophoresis 25, 3336-3343. doi: 10.1002/elps.200 406068

Li, S., Jin, M., Koeglsperger, T., Shepardson, N. E., Shankar, G. M., and Selkoe, D. J. (2011). Soluble Abeta oligomers inhibit long-term potentiation through a mechanism involving excessive 
activation of extrasynaptic NR2Bcontaining NMDA receptors. J. Neurosci. 31, 6627-6638. doi: 10.1523/JNEUROSCI.0203-11.2011

Lue, L. F., Kuo, Y. M., Roher, A. E., Brachova, L., Shen, Y., Sue, L., et al. (1999). Soluble amyloid beta peptide concentration as a predictor of synaptic change in Alzheimer's disease. Am. J. Pathol. 155, 853-862. doi: 10.1016/S00029440(10)65184-X

Magleby, K. L. (1987). "Short-term changes in synaptic efficacy," in Synaptic Function, eds G. M. Edelman, W. E. Gall, and W. M. Cowan (New York, NY: Wiley), 21-56.

Markram, H., Wang, Y., and Tsodyks, M. (1998). Differential signaling via the same axon of neocortical pyramidal neurons. Proc. Natl. Acad. Sci. U.S.A. 95, 5323-5328. doi: 10.1073/pnas.95.9.5323

Minano-Molina, A. J., Espana, J., Martin, E., Barneda-Zahonero, B., Fado, R., Sole, M., et al. (2011). Soluble oligomers of amyloid-beta peptide disrupt membrane trafficking of alpha-amino-3-hydroxy-5methylisoxazole-4-propionic acid receptor contributing to early synapse dysfunction. J. Biol. Chem. 286, 27311-27321. doi: 10.1074/jbc.M111.227504

Minkeviciene, R., Rheims, S., Dobszay, M. B., Zilberter, M., Hartikainen, J., Fulop, L., et al. (2009). Amyloid beta-induced neuronal hyperexcitability triggers progressive epilepsy. J. Neurosci. 29, 3453-3462. doi: 10.1523/ JNEUROSCI.5215-08.2009

Mongillo, G., Barak, O., and Tsodyks, M. (2008). Synaptic theory of working memory. Science 319, 1543-1546. doi: 10.1126/science.1150769

Moreno, H., Yu, E., Pigino, G., Hernandez, A. I., Kim, N., Moreira, J. E., et al. (2009). Synaptic transmission block by presynaptic injection of oligomeric amyloid beta. Proc. Natl. Acad. Sci. U.S.A. 106, 5901-5906. doi: 10.1073/pnas.0900944106

Morris, R. G., and Baddeley, A. D. (1988). Primary and working memory functioning in Alzheimer-type dementia. J. Clin. Exp. Neuropsychol. 10, 279-296. doi: $10.1080 / 0168863880$ 8408242

Nimmrich, V., and Ebert, U. (2009). Is Alzheimer's disease a result of presynaptic failure. Synaptic dysfunctions induced by oligomeric beta-amyloid.
Rev. Neurosci. 20, 1-12. doi: 10.1515/REVNEURO.2009.20.1.1

Nimmrich, V., Grimm, C., Draguhn, A., Barghorn, S., Lehmann, A., Schoemaker, H., et al. (2008). Amyloid beta oligomers (A beta(1-42) globulomer) suppress spontaneous synaptic activity by inhibition of P/Q-type calcium currents. J. Neurosci. 28, 788-797. doi: 10.1523/JNEUROSCI.4771-07.2008

Palop, J. J., and Mucke, L. (2010). Amyloid-beta-induced neuronal dysfunction in Alzheimer's disease: from synapses toward neural networks. Nat. Neurosci. 13, 812-818. doi: 10.1038/nn.2583

Papadia, S., and Hardingham, G. E. (2007). The dichotomy of NMDA receptor signaling. Neuroscientist $13,572-579$.

Parihar, M. S., and Brewer, G. J. (2010). Amyloid-beta as a modulator of synaptic plasticity. J. Alzheimers Dis. 22, 741-763.

Puchtler, H., and Sweat, F. (1962). Amidoblack as a stain for hemoglobin. Arch. Pathol. 73, 245-249.

Puzzo, D., Privitera, L., Leznik, E., Fa, M., Staniszewski, A., Palmeri, A., et al. (2008). Picomolar amyloid-beta positively modulates synaptic plasticity and memory in hippocampus. J. Neurosci. 28, 14537-14545. doi: 10.1523/JNEUROSCI.2692-08.2008

Ramsden, M., Henderson, Z., and Pearson, H. A. (2002). Modulation of $\mathrm{Ca} 2+$ channel currents in primary cultures of rat cortical neurones by amyloid beta protein (1$40)$ is dependent on solubility status. Brain Res. 956, 254-261. doi: 10.1016/S0006-8993(02)03547-3

Reid, W., Broe, G., Creasey, H., Grayson, D., McCusker, E., Bennett, H., et al. (1996). Age at onset and pattern of neuropsychological impairment in mild early-stage Alzheimer disease. A study of a community-based population. Arch. Neurol. 53, 1056-1061. doi: 10.1001/archneur.1996.00550100142023

Ronicke, R., Mikhaylova, M., Ronicke, S., Meinhardt, J., Schroder, U. H., Fandrich, M., et al. (2011). Early neuronal dysfunction by amyloid beta oligomers depends on activation of NR2Bcontaining NMDA receptors. Neurobiol. Aging 32, 2219-2228. doi: $\quad 10.1016 / j$. neurobiolaging. 2010.01.011

Rowan, M. J., Klyubin, I., Cullen, W. K., and Anwyl, R. (2003). Synaptic plasticity in animal models of early Alzheimer's disease. Philos. Trans. R.
Soc. Lond. B Biol. Sci. 358, 821-828. doi: $10.1098 /$ rstb.2002.1240

Selkoe, D. J. (2002). Alzheimer's disease is a synaptic failure. Science 298, 789-791. doi 10.1126/science. 1074069

Shankar, G. M., Li, S., Mehta, T. H., Garcia-Munoz, A., Shepardson, N. E., Smith, I., et al. (2008). Amyloidbeta protein dimers isolated directly from Alzheimer's brains impair synaptic plasticity and memory. Nat. Med. 14, 837-842. doi: $10.1038 / \mathrm{nm} 1782$

Shemer, I., Holmgren, C., Min, R., Fulop, L., Zilberter, M., Sousa, K. M., et al. (2006). Non-fibrillar beta-amyloid abates spike-timingdependent synaptic potentiation at excitatory synapses in layer $2 / 3$ of the neocortex by targeting postsynaptic AMPA receptors. Eur. J. Neurosci. 23, 2035-2047. doi 10.1111/j.1460-9568.2006.04733.x

Simons, J. S., and Spiers, H. J. (2003). Prefrontal and medial temporal lobe interactions in long-term memory. Nat. Rev. Neurosci. 4, 637-648. doi: $10.1038 / \mathrm{nrn} 1178$

Small, D. H., Gasperini, R., Vincent, A. J., Hung, A. C., and Foa, L. (2009). The role of Abeta-induced calcium dysregulation in the pathogenesis of Alzheimer's disease. J. Alzheimers Dis. 16, 225-233.

Snyder, S. W., Ladror, U. S., Wade, W. S., Wang, G. T., Barrett, L. W., Matayoshi, E. D., et al. (1994). Amyloid-beta aggregation: selective inhibition of aggregation in mixtures of amyloid with different chain lengths. Biophys. J. 67, 1216-1228. doi: 10.1016/S0006-3495(94)80591-0

Stanika, R. I., Pivovarova, N. B., Brantner, C. A., Watts, C. A. Winters, C. A., and Andrews, S. B. (2009). Coupling diverse routes of calcium entry to mitochondrial dysfunction and glutamate excitotoxicity. Proc. Natl. Acad. Sci. U.S.A. 106, 9854-9859. doi 10.1073/pnas.0903546106

Stine, W. B. Jr., Dahlgren, K. N. Krafft, G. A., and $\mathrm{LaDu}, \mathrm{M}$. J. (2003). In vitro characterization of conditions for amyloid-beta peptide oligomerization and fibrillogenesis. J. Biol. Chem. 278, 11612-11622. doi: 10.1074/jbc. M210207200

Tamse, C. T., Xu, Y., Song, H., Nie, L., and Yamoah, E. N. (2003). Protein kinase A mediates voltagedependent facilitation of $\mathrm{Ca} 2+$ current in presynaptic hair cells in Hermissenda crassicornis. J. Neurophysiol. 89, 1718-1726. doi: 10.1152/jn.00766.2002
Teunissen, C. E., de Vente, J., Steinbusch, H. W., and De Bruijn, C. (2002). Biochemical markers related to Alzheimer's dementia in serum and cerebrospinal fluid. Neurobiol. Aging 23, 485-508. doi: 10.1016/S0197-4580(01)00328-1

Tsodyks, M., Uziel, A., and Markram, H. (2000). Synchrony generation in recurrent networks with frequencydependent synapses. J. Neurosci. 20, RC50.

Tsodyks, M. V., and Markram, H. (1997). The neural code between neocortical pyramidal neurons depends on neurotransmitter release probability. Proc. Natl. Acad. Sci. U.S.A. 94, 719-723. doi: 10.1073/pnas.94.2.719

Venkitaramani, D. V., Chin, J., Netzer, W. J., Gouras, G. K., Lesne, S., Malinow, R., et al. (2007). Beta-amyloid modulation of synaptic transmission and plasticity. J. Neurosci. 27, 11832-11837.

doi: 10.1523/JNEUROSCI.3478-07.2007

Walsh, D. M., Klyubin, I., Fadeeva, J. V., Cullen, W. K., Anwyl, R., Wolfe, M. S., et al. (2002). Naturally secreted oligomers of amyloid beta protein potently inhibit hippocampal long-term potentiation in vivo. Nature 416, 535-539. doi: 10.1038/ $416535 \mathrm{a}$

Wang, D., and Al, E. (2001). "Amyloid, PHF-tau, ubiquitin and synaptic markers: analysis of frontal cortex from prospectively studied elderly humans," in Alzheimer's Disease: Advances in Etiology, Pathogenesis and Therapeutics, eds K. Iqbal, S. Sisodia, and B. Wingblad (Hoboken, NJ: John Wiley and Sons).

Wang, Q., Walsh, D. M., Rowan, M. J., Selkoe, D. J., and Anwyl, R. (2004). Block of long-term potentiation by naturally secreted and synthetic amyloid beta-peptide in hippocampal slices is mediated via activation of the kinases c-Jun Nterminal kinase, cyclin-dependent kinase 5, and p38 mitogenactivated protein kinase as well as metabotropic glutamate receptor type 5. J. Neurosci. 24, 3370-3378. doi: 10.1523/JNEUROSCI.163303.2004

Wang, Y., Gupta, A., Toledo-Rodriguez, M., Wu, C. Z., and Markram, H. (2002). Anatomical, physiological, molecular and circuit properties of nest basket cells in the developing somatosensory cortex. Cereb. Cortex 12, 395-410. doi: 10.1093/cercor/12.4.395

Wang, Y., Markram, H., Goodman, P. H., Berger, T. K., Ma, J., and 
Goldman-Rakic, P. S. (2006). Heterogeneity in the pyramidal network of the medial prefrontal cortex. Nat. Neurosci. 9, 534-542. doi: 10.1038/ nn 1670

Wang, Y., Zhang, G., Zhou, H., Barakat, A., and Querfurth, H. (2009). Opposite effects of low and high doses of Abeta42 on electrical network and neuronal excitability in the rat prefrontal cortex. PLoS ONE 4:e8366. doi: 10.1371/journal.pone.0008366

Wu, J., Anwyl, R., and Rowan, M. J. (1995). beta-Amyloid(1-40) increases long-term potentiation in rat hippocampus in vitro. Eur. J. Pharmacol. 284, R1-R3. doi: 10.1016/0014-2999 (95)00539-W

Zhuo, J. M., Prakasam, A., Murray, M. E., Zhang, H. Y., Baxter, M. G., Sambamurti, K., et al. (2008). An increase in Abeta42 in the prefrontal cortex is associated with a reversal-learning impairment in Alzheimer's disease model Tg2576 APPsw mice. Curr. Alzheimer Res. 5, 385-391. doi: 10.2174/1567205087 85132280

Zucker, R. S., and Regehr, W. G. (2002). Short-term synaptic plasticity. Annu. Rev. Physiol. 64, 355-405. doi: $\quad 10.1146 /$ annurev.physiol.64 092501.114547

Conflict of Interest Statement: The authors declare that the research was conducted in the absence of any commercial or financial relationships that could be construed as a potential conflict of interest.

Received: 11 April 2013; accepted: 29 July 2013; published online: 03 September 2013.

Citation: Wang Y, Zhou TH, Zhi Z, Barakat A, Hlatky L and Querfurth $H$ (2013) Multiple effects of $\beta$-amyloid on single excitatory synaptic connections in the PFC. Front. Cell. Neurosci. 7:129. doi: 10.3389/fncel.2013.00129

This article was submitted to the journal Frontiers in Cellular Neuroscience.

Copyright (c) 2013 Wang, Zhou, Zhi, Barakat, Hlatky and Querfurth. This is an open-access article distributed under the terms of the Creative Commons Attribution License (CC BY). The use, distribution or reproduction in other forums is permitted, provided the original author(s) or licensor are credited and that the original publication in this journal is cited, in accordance with accepted academic practice. No use, distribution or reproduction is permitted which does not comply with these terms. 


\section{APPENDIX}

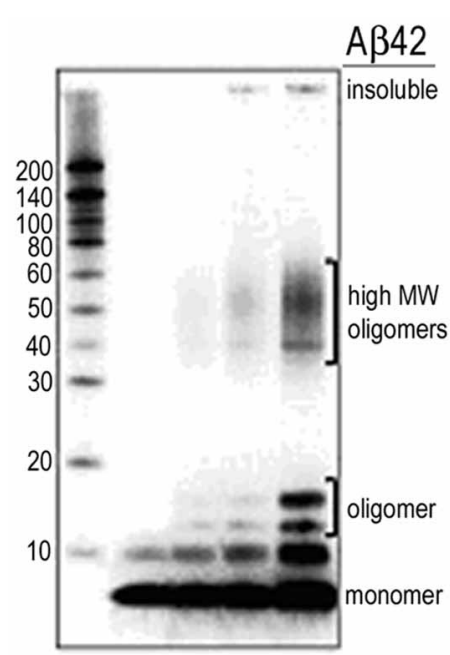

FIGURE A1 | Western blot monitoring of A $\boldsymbol{\beta}$ stock solutions. Monomer predominant preps as shown in lane 1 were used for the recording of single synaptic connections. Synthetic $A \beta$ peptides were solubilized in 1,1,1,3,3,3-hexafluoro-2-propanol (HFIP), aliquoted, dried and stored at $-80^{\circ} \mathrm{C}$. A working stock solution $(0.1 \mathrm{mM})$ was then prepared and stored at $-80^{\circ} \mathrm{C}$ for dilution immediately before use. Aged or oligomerized preps as appear in lane 5 were not used in the current work.
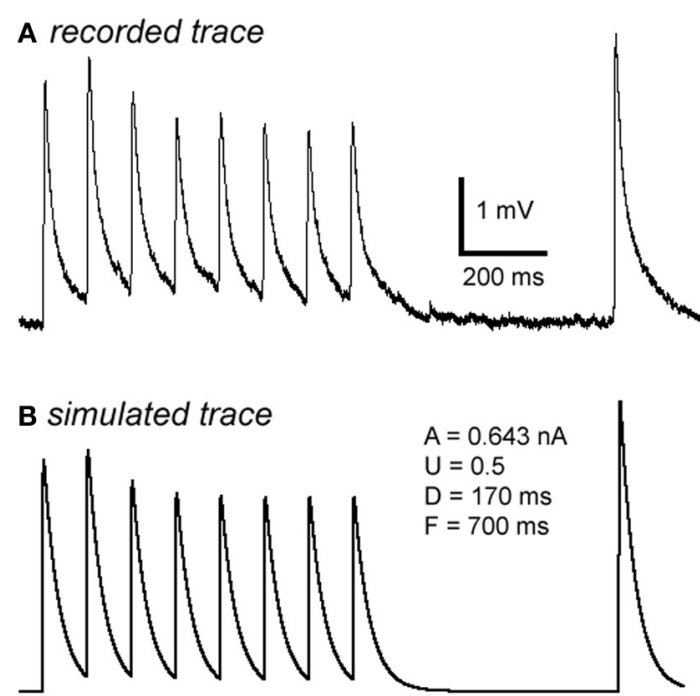

FIGURE A2 | Computer simulation of synaptic responses. The $10 \mathrm{~Hz}$ EPSP train followed by a RTR with $500 \mathrm{~ms}$ delay was recorded from a PC-IN connection (A). Using a model of dynamic synaptic transmission, the synaptic dynamics were assessed by fitting the EPSPs (B). The modeling extracts four key parameters of the connection: DFUA ( $D$, the time constant of recovery from depression; $F$, the time constant of recovery from facilitation; $U$, utilization of synaptic resources used analogously to release probability, $p$; $A$, the absolute synaptic strength). If samplings were big enough, these parameters could be quantitatively analyzed enabling a quantitative comparison of basal synaptic dynamic changes induced by $A \beta$. Trends of changes induced by $A \beta$ were revealed despite low samplings in most data sets (see Table A1).

Table A1 | Changes of synaptic dynamic properties in the modeling analysis.

\begin{tabular}{|c|c|c|c|c|c|c|c|c|}
\hline & & & & $A$ & $\boldsymbol{U}$ & $D$ & $\boldsymbol{F}$ & $F / D$ \\
\hline & & & $A \beta(n=11)$ & 3.17 & 0.29 & 248 & 926 & 3.73 \\
\hline & Figure 3B & D-connection & control $(n=6)$ & 2.61 & 0.50 & 359 & 165 & 0.46 \\
\hline \multirow{5}{*}{ High-dose $A \beta 40 \& A \beta 25-35$} & & & $A \beta(n=6)$ & 2.21 & 0.39 & 623 & 457 & 0.73 \\
\hline & Figure 3C & F-connection & control $(n=3)$ & 4.68 & 0.32 & 235 & 807 & 3.43 \\
\hline & & & $\mathrm{A} \beta(n=3)$ & 3.92 & 0.26 & 243 & 905 & 3.73 \\
\hline & & & washout $(n=3)$ & 9.75 & 0.28 & 200 & 896 & 4.49 \\
\hline & Figure 3D & D-connection & control $(n=6)$ & 1.83 & 0.48 & 679 & 149 & 0.22 \\
\hline \multirow{4}{*}{ Low-dose Ab42 } & & & $A \beta(n=5)$ & 1.36 & 0.42 & 430 & 465 & 1.08 \\
\hline & Figure 3F & D-connection & control $(n=5)$ & 3.71 & 0.55 & 646 & 119 & 0.18 \\
\hline & & & $A \beta(n=5) 2.90$ & 0.45 & 826 & 114 & 0.14 & \\
\hline & & & washout $(n=3)$ & 2.54 & 0.47 & 825 & 142 & 0.17 \\
\hline
\end{tabular}

